\title{
Samarium Coordinated Polymer: Structural, Vibrational and Thermal Studies of $\left[\mathrm{Sm}_{2}\left(\mathrm{C}_{3} \mathrm{H}_{2} \mathrm{O}_{4}\right)_{3}\left(\mathrm{H}_{2} \mathrm{O}\right)_{6}\right]_{n}$
}

\author{
B. H. Doreswamy $\cdot$ M. Mahendra • \\ J. Shashidhara Prasad • P. A. Varughese • \\ George Varghese
}

Received: 13 September 2010/ Accepted: 2 December 2010/Published online: 19 December 2010

(C) Springer Science+Business Media, LLC 2010

\begin{abstract}
The title compound, $\left[\mathrm{Sm}_{2}\left(\mathrm{C}_{3} \mathrm{H}_{2} \mathrm{O}_{4}\right)_{3}\left(\mathrm{H}_{2} \mathrm{O}\right)_{6}\right]$, was investigated by $\mathrm{X}$-ray diffraction. It crystallizes in the monoclinic space group $C 2 / c$ with cell parameters $a=17.1650(8) \AA, b=12.3010(5) \AA, c=11.1420(4) \AA$, $\beta=127.5161(10)^{\circ}, Z=4$ and $V=1866.04(14) \AA^{3}$. The $\mathrm{Sm}$ atom lies on a two-fold axis and has nine-coordination with six oxygen atoms from carboxylate groups and three water molecules. The compound forms a layer-type polymeric structure. The layers are formed by samarium and one independent malonate group to give a three-dimensional framework. The extensive network of hydrogen bonds and bridge bonds observed in this structure enhances the structural stability. The thermal dehydration of the compound was investigated by thermogravimetric analysis.
\end{abstract}

Keywords Samarium - Malonate hydrates · FTIR - TGA · $\mathrm{X}$-ray crystal structure

\section{Introduction}

In the vast field of materials science and technology, rare earths or rare earth-related compounds are of immense

B. H. Doreswamy

Department of Physics, SJB Institute of Technology,

Kengeri, Bangalore 560 060, India

M. Mahendra $(\bowtie) \cdot$ J. Shashidhara Prasad

Department of Studies in Physics, University of Mysore,

Mysore 570 006, India

e-mail: mahendra@physics.uni-mysore.ac.in

P. A. Varughese - G. Varghese

Crystal Physics Centre, St. Berchmans' College,

Changanachery 686101 , Kerala, India interest due to their many interesting and peculiar properties [1-6]. Many researchers have carried out extensive work on dicarboxylates of rare earth elements (e.g., oxalates [7-9], malonates [10, 11], maleates [12, 13], tartrates [14] owing to their important applications. However, little has been done on rare earth malonates. In our current study, we have investigated a samarium complex with malonate as a ligand and different water of hydrations. An interesting feature of the malonate ligand is that it exhibits flexible stereochemistry and variable modes of binding with metal ions in the crystalline state [15-25]. It is also characterized by an active methylene $\left(-\mathrm{CH}_{2}-\right)$ group between two carboxylate groups. Three bonding modes, S1, S2 and S3 (Fig. 1) have been observed. In this report, the flexible coordination ability of samarium is discussed; it adopts the S2 and S3 bonding mode; i.e., monodentate, chelating and bridging [15-25]. In view of the above, we report here the growth of $\left[\mathrm{Sm}_{2}\left(\mathrm{C}_{3} \mathrm{H}_{2} \mathrm{O}_{4}\right)_{3}\left(\mathrm{H}_{2} \mathrm{O}\right)_{6}\right]_{\mathrm{n}}(\mathbf{1})$ crystals by the gel technique [26] and the $\mathrm{X}$-ray crystal study to discern the coordination geometry around the rare earth. In addition, we report the Fourier transform infrared (FT-IR) spectrum and thermogravimetric analysis (TGA) of $\mathbf{1}$.

\section{Experimental}

Pale yellow colored single crystals of $\mathbf{1}$ were prepared using the diffusion-reaction process inside a non-reacting gel medium. The growth medium of hydrosilica gel was prepared by titrating sodium metasilicate solution (specific gravity $\left.=1.03 \mathrm{~g} \mathrm{~cm}^{-3}\right)$ with malonic acid $(1 \mathrm{M}$, purity $99.99 \%$ ) to $\mathrm{pH}$ 5.5. This solution was then poured into glass tubes having an internal diameter of $18 \mathrm{~mm}$ and kept undisturbed for gel formation. After 3 days, the samarium chloride solution $(0.2 \mathrm{M}$, purity $99.999 \%)$ was poured over 
<smiles>OC1CC2OC(CC2O)O1</smiles>

(S1)

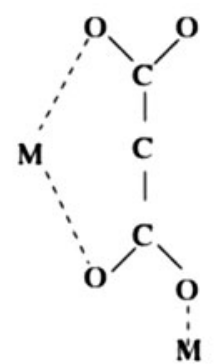

(S2)

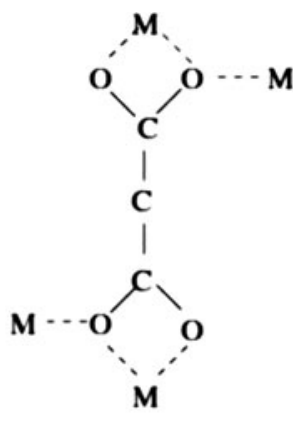

(S3)
Fig. 1 Bonding mode, S1, S2 and S3, of the malonate ligand where $\mathrm{M}=\mathrm{Cu}, \mathrm{Co}, \mathrm{Eu}, \mathrm{Cr}$ for $\mathrm{S} 1, \mathrm{M}=\mathrm{Pr}, \mathrm{Eu}, \mathrm{Cu}, \mathrm{Sc}, \mathrm{Zn}, \mathrm{Nd}$ for $\mathrm{S} 2$ and $\mathrm{M}=\mathrm{Eu}, \mathrm{Pr}, \mathrm{Na}$ for $\mathrm{S} 3$

the gel column and kept tranquil to initiating the diffusion process and subsequent chemical reaction for the crystallization of samarium malonate (Eq. 1). Faceted crystals of average size $4 \times 1 \times 0.6 \mathrm{~mm}^{3}$ were obtained in $4-5$ weeks after initiation of the reaction process.

$$
\begin{aligned}
& 2 \mathrm{SmCl}_{3} \cdot 6 \mathrm{H}_{2} \mathrm{O}+3 \mathrm{CH}_{2}(\mathrm{COOH})_{2} \\
& \quad \rightarrow \mathrm{Sm}_{2}\left(\mathrm{C}_{3} \mathrm{H}_{2} \mathrm{O}_{4}\right)_{3} \cdot 6 \mathrm{H}_{2} \mathrm{O}+6 \mathrm{HCl}
\end{aligned}
$$

The infrared spectra from $4000-400 \mathrm{~cm}^{-1}$ were carried out with a Bruker IFS66 spectrophotometer as a $\mathrm{KBr}$ pellet.

Table 1 Crystallographic data of 1

\begin{tabular}{ll}
\hline Empirical formula & $\mathrm{C}_{9} \mathrm{H}_{18} \mathrm{O}_{18} \mathrm{Sm}_{2}$ \\
Formula weight & 714.93 \\
Temperature & $293(2) \mathrm{K}$ \\
Wavelength & $0.71073 \AA$ \\
Crystal system, space group & Monoclinic, C2/c \\
Unit cell dimensions & $a=17.1650(8) \AA$ \\
& $b=12.3010(5) \AA$ \\
& $c=11.1420(5) \AA$ \\
& $\beta=127.5161(10)^{\circ}$ \\
Volume & $1866.04(14) \AA^{3}$ \\
Z, Calculated density & $4,2.545 \mathrm{Mg} / \mathrm{m}^{3}$ \\
Absorption coefficient & $6.324 \mathrm{~mm}{ }^{-1}$ \\
$F(000)$ & 1360 \\
Crystal size & $0.2 \times 0.2 \times 0.2 \mathrm{~mm}$ \\
Theta range for data collection & $21.97-32.48^{\circ}$ \\
Limiting indices & $25 \leq h \leq 25,-13 \leq k \leq 13$, \\
& $-16 \leq l \leq 16$ \\
Reflections collected/unique & $3279 / 1748[R(\mathrm{int})=0.0201]$ \\
Refinement method & Full-matrix least-squares on $F^{2}$ \\
Data/restraints/parameters & $1748 / 0 / 132$ \\
Goodness-of-fit on $F^{2}$ & 1.142 \\
Final $R$ indices $[I>2 \sigma(I)]$ & $R_{1}=0.0425, \mathrm{w} R_{2}=0.1214$ \\
$R$ indices (all data) & $R_{1}=0.0438, \mathrm{w} R_{2}=0.1229$ \\
Largest diff. peak and hole & 1.524 and $-1.408 \mathrm{e} . \AA^{-3}$ \\
\hline
\end{tabular}

The resolution of the instrument was better than $4 \mathrm{~cm}^{-1}$. All the characteristic bands of the compound are observed in the spectrum.

Thermogravimetric analysis of $\mathbf{1}$ was performed on a STA 1500 thermal analysis system. The compound was heated from ambient temperature to $900{ }^{\circ} \mathrm{C}$ at a heating rate of $10{ }^{\circ} \mathrm{C}$ per minute under nitrogen.

A single crystal of $\mathbf{1}$ of dimensions $0.2 \times 0.2 \times$ $0.2 \mathrm{~mm}^{3}$ was chosen for X-ray diffraction studies. The measurements were made on a DIPLabo Imaging Plate system with graphite monochromated $\mathrm{MoK}_{\alpha}$ radiation $(\lambda=0.71073 \AA)$. Thirty-six frames of data were collected using the oscillation method. Successive frames were scanned in steps of $5^{\circ} / \mathrm{min}$ with an oscillation range of $5^{\circ}$. Image processing and data reduction were done using Denzo [27]. The structure was solved and refined using the maXus [28-30] program. All the non-hydrogen atoms were revealed in the first map. Initially, full-matrix least-squares refinement was performed using 1,748 observed reflections $(I>2 \sigma(I))$ for all the non-hydrogen atoms with isotropic temperature factors; the residual at this stage converged to $R=0.0897$. The hydrogen atoms were placed at calculated positions and were refined with isotropic temperature factors. Refinement of non-hydrogen atoms with anisotropic thermal parameters was started at this stage. After ten cycles of refinement, the residuals saturated at $R=0.0425$. The details of crystal data, data collection and refinement are given in Table 1.

\section{Results and Discussion}

\subsection{Spectral Analysis}

The FT-IR spectral study reveals the bonding structure of the 1. The spectrum (Fig. 2) was interpreted by comparing with those of malonic acid and related compounds [31-34]. In 1, the internal vibrations are mainly due to carboxylate group, methylene group and water molecules. The most interesting frequencies with respect to structure are those of $\mathrm{C}-\mathrm{O}$ vibrations. These are assigned (Table 2) to the asymmetric and symmetric stretching modes of the carboxylate group. The highly intense bands at 1564 and $1381 \mathrm{~cm}^{-1}$ are ascribed to the asymmetric stretching and symmetric stretching modes of the carboxylate group, respectively. The lowering of both the stretching frequencies is due to the drainage of the electron density from the carboxylate group to the metal to form chelates or bridges between carboxylates. The medium bands at 711 and $650 \mathrm{~cm}^{-1}$ are ascribed to the bending modes of the carboxylate group.

The asymmetric and symmetric stretching modes of methylene group are observed as weak bands at 2986 and 
Fig. 2 FTIR spectrum of 1

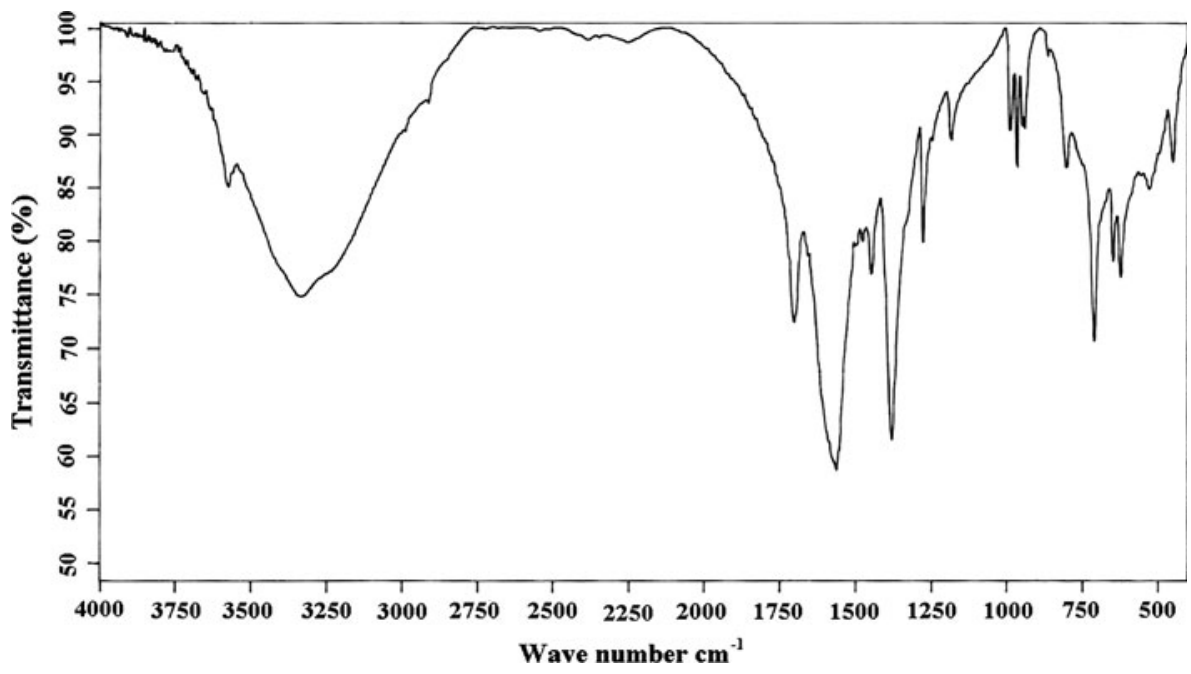

Table 2 Absorption wave numbers and proposed assignments of $\mathbf{1}$

\begin{tabular}{|c|c|}
\hline Wave number $\left(\mathrm{cm}^{-1}\right)$ & Assignments \\
\hline 3332(svbr) & $v \mathrm{OH}$ \\
\hline 2986(w) & $v_{\text {as }} \mathrm{CH}_{2}$ \\
\hline 2912(w) & $v_{\mathrm{s}} \mathrm{CH}_{2}$ \\
\hline 1703(s) & $\delta \mathrm{H}_{2} \mathrm{O}$ \\
\hline 1564(vsbr) & $v_{\text {as }} \mathrm{OCO}$ \\
\hline $1502(\mathrm{~m})$ & $v_{\text {as }} \mathrm{OCO}$ \\
\hline $1478(\mathrm{~m})$ & $\delta \mathrm{CH}_{2}$ \\
\hline 1449(m) & $\delta \mathrm{CH}_{2}$ \\
\hline 1381(vs) & $v_{\mathrm{s}} \mathrm{OCO}$ \\
\hline $1278(\mathrm{~m})$ & $\omega \mathrm{CH}_{2}$ \\
\hline 1244(w) & $\omega \mathrm{CH}_{2}$ \\
\hline $1185(w)$ & $v_{\text {as }} \mathrm{CC}$ \\
\hline $967(w)$ & $v_{\mathrm{s}} \mathrm{CC}$ \\
\hline $950(w)$ & $v_{\mathrm{s}} \mathrm{CC}$ \\
\hline $990(w)$ & $\rho \mathrm{CH}_{2}$ \\
\hline $941(w)$ & $\rho \mathrm{CH}_{2}$ \\
\hline 866(vw) & $\delta \mathrm{CC}$ \\
\hline $803(w)$ & $\rho \mathrm{H}_{2} \mathrm{O}$ \\
\hline 711(s) & $\delta \mathrm{OCO}$ \\
\hline $650(\mathrm{~m})$ & $\delta \mathrm{OCO}$ \\
\hline $625(\mathrm{~m})$ & $\delta \mathrm{CCO}$ \\
\hline $531(w)$ & $\omega, \mathrm{t} \mathrm{H}_{2} \mathrm{O}$ \\
\hline 482(m) & $\omega, \mathrm{t} \mathrm{H}_{2} \mathrm{O}$ \\
\hline 453(w) & $v \mathrm{M}-\mathrm{OH}_{2}$ \\
\hline
\end{tabular}

Note. $v$ stretching, $v_{\text {as }}$ asymmetric stretching, $v_{\mathrm{s}}$ symmetric stretching, $\delta$ bending, $\omega$ wagging, $\rho$ rocking, $t$ twisting, $s$ strong, $s v b r$ strong and very broad, $v s$ very strong, $v s b r$ very strong and broad, $m$ medium, $w$ weak, $v w$ very weak

$2912 \mathrm{~cm}^{-1}$, while the bending modes are associated with the medium bands at 1478 and $1449 \mathrm{~cm}^{-1}$. The medium band at $1278 \mathrm{~cm}^{-1}$ and the weak band at $1244 \mathrm{~cm}^{-1}$ are due to $-\mathrm{CH}_{2}$ - wagging. In addition, the rocking modes of this group are observed as weak bands at 990 and $941 \mathrm{~cm}^{-1}$.

The weak bands at 1185,967 and $950 \mathrm{~cm}^{-1}$ are attributed to the $\mathrm{C}-\mathrm{C}$ stretching modes. The $\mathrm{C}-\mathrm{C}$ bending mode is seen as a very weak band at $866 \mathrm{~cm}^{-1}$. A medium band at $625 \mathrm{~cm}^{-1}$ is assigned to the $\mathrm{C}-\mathrm{CO}$ bending mode.

The presence of water of hydration in $\mathbf{1}$ is evidenced by the strong and very broad band centered at $3332 \mathrm{~cm}^{-1}$. This is due to the $\mathrm{O}-\mathrm{H}$ stretching vibration. There is a decrease in frequency, which indicates hydrogen bonding. The bending mode of water is observed as a strong band at $1703 \mathrm{~cm}^{-1}$ whereas the rocking mode is a weak band at $803 \mathrm{~cm}^{-1}$. The weak band at $531 \mathrm{~cm}^{-1}$ is ascribed to the wagging and twisting modes of water. Also, a weak band at $453 \mathrm{~cm}^{-1}$ is attributed to the $\mathrm{M}-\mathrm{OH}_{2}$ stretching vibration.

\subsection{Thermogravimetric Analysis}

Thermogravimetric (TG) study reveals that $\mathbf{1}$ is stable to $133{ }^{\circ} \mathrm{C}$. The TG curve of $\mathbf{1}$ (Fig. 3) shows a three-stage thermal decomposition. Dehydration occurs in the first stage $\left(133-202{ }^{\circ} \mathrm{C}\right)$ in which all the six waters of hydration are lost. Above $133{ }^{\circ} \mathrm{C}$, the TG of anhydrous malonate is a plateau and is transformed into the oxycarbonate of the metal and elementary carbon $\left(323-399{ }^{\circ} \mathrm{C}\right)$. In the final decomposition stage $\left(399-810{ }^{\circ} \mathrm{C}\right)$ the oxycarbonate is decomposed to yield the metal oxide. The residue comprises a mixture of elementary carbon and the metal oxide. The thermal decomposition occurring in each stage may be described as follows:

$\mathrm{Sm}_{2}\left(\mathrm{C}_{3} \mathrm{H}_{2} \mathrm{O}_{4}\right)_{3} \cdot 6 \mathrm{H}_{2} \mathrm{O} \stackrel{133-202^{\circ} \mathrm{C}}{\longrightarrow} \mathrm{Sm}_{2}\left(\mathrm{C}_{3} \mathrm{H}_{2} \mathrm{O}_{4}\right)_{3}+6 \mathrm{H}_{2} \mathrm{O}$ 
Fig. 3 TGA curve of $\mathbf{1}$

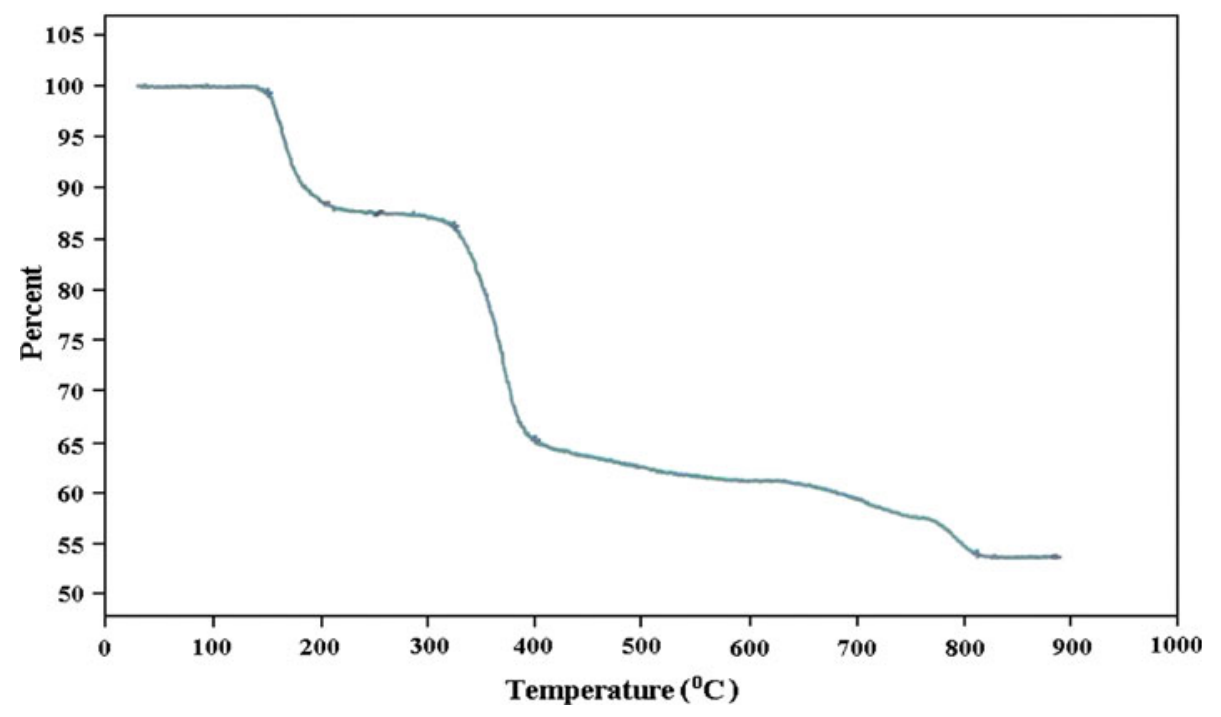

Table 3 Thermal decomposition data of $\mathbf{1}$

\begin{tabular}{llllll}
\hline Stage & Temperature range $\left({ }^{\circ} \mathrm{C}\right)$ & Mass loss $\%$ & & Leaving groups & $\frac{\%}{\% \text { of metal oxide }+ \text { carbon }}$ \\
\cline { 3 - 4 } & & Observed & Calculated & & Observed \\
\hline 1 & $133-202$ & 14.50 & 15.13 & $6 \mathrm{H}_{2} \mathrm{O}$ & \\
2 & $323-399$ & 19.50 & 19.89 & $2 \mathrm{CO}_{2}, 3 \mathrm{H}_{2} \mathrm{O}$ & 53.95 \\
3 & $399-810$ & 12.05 & 11.76 & $2 \mathrm{CO}$ & 53.22 \\
\hline
\end{tabular}

Fig. 4 Perspective ORTEP [45] diagram of 1 with thermal ellipsoids at $50 \%$ probability. $\mathrm{H}$ atoms have been omitted for clarity [Symmetry codes: $a=(1 / 2-x, 1 / 2-y,-z)$,

$b=(-1 / 2+x, 1 / 2-y$,

$-1 / 2+z), c=(x, 1-y$,

$-1 / 2+z), d=(-1 / 2+x$,

$-1 / 2+y,-1+z)$

$e=(1 / 2-x$,

$-1 / 2+y, 1 / 2-z), f=(1-x, y$

$1 / 2-z)$ and $g=(-x, 1-y,-z)]$

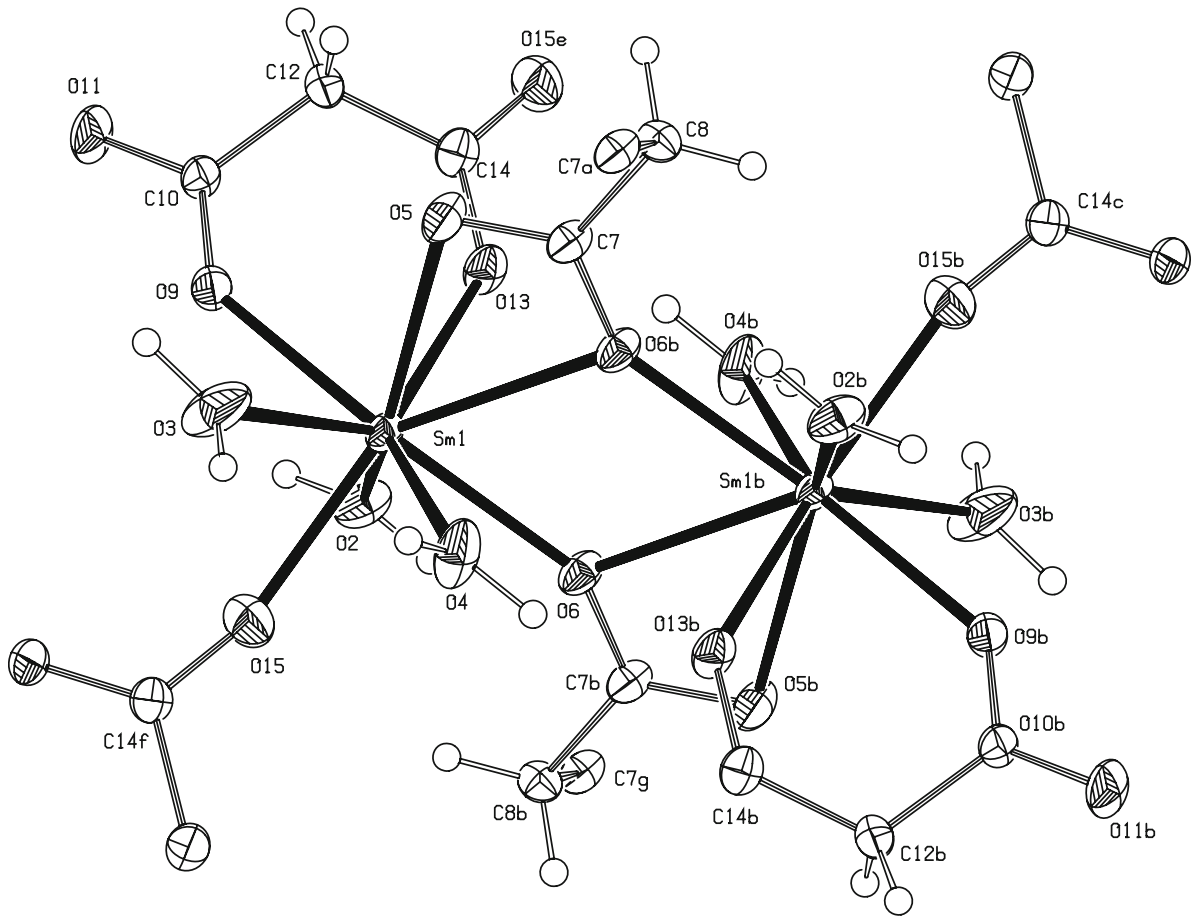




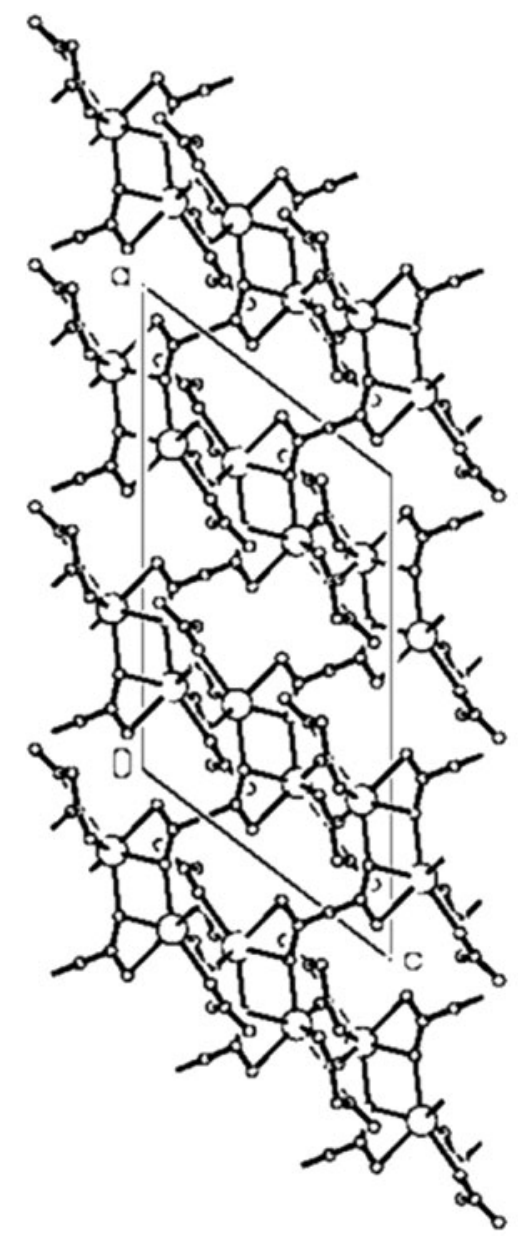

Fig. 5 Packing of the molecules along the $b$ axis. Water molecules and $\mathrm{H}$ atoms have been omitted for the sake of clarity

$$
\begin{aligned}
\mathrm{Sm}_{2}\left(\mathrm{C}_{3} \mathrm{H}_{2} \mathrm{O}_{4}\right)_{3} \stackrel{323-399^{\circ} \mathrm{C}}{\longrightarrow} & \mathrm{Sm}_{2} \mathrm{O}_{2} \mathrm{CO}_{3}+2 \mathrm{CO}_{2}+3 \mathrm{H}_{2} \mathrm{O} \\
& +6 \mathrm{C}
\end{aligned}
$$

$\mathrm{Sm}_{2} \mathrm{O}_{2} \mathrm{CO}_{3}+\mathrm{C} \stackrel{399-810^{\circ} \mathrm{C}}{\longrightarrow} \mathrm{Sm}_{2} \mathrm{O}_{3}+2 \mathrm{CO}$

The percentage of mass losses observed is in good agreement with the calculated values (Table 3 ). The weight losses due to hydration, coordinated water molecules and decomposed organic moiety of the organic ligand are in agreement with those found for other compounds described in the literature [35-41].

\subsection{Crystal Structure Analysis}

A perspective drawing showing the coordination geometry, labeling scheme and $50 \%$ probability displacement ellipsoid is shown in Fig. 4. The packing of the molecules in $\mathbf{1}$ along the axes exhibit a three-dimensional layer-type polymeric framework (Figs. 5, 6).
The layers are formed by three types of rings; i.e., $\mathrm{Sm}-\mathrm{O}-\mathrm{C}-\mathrm{O}$ and $\mathrm{Sm}-\mathrm{O}-\mathrm{C}-\mathrm{C}-\mathrm{C}-\mathrm{O}$ chelate rings formed by bidentate coordination and $\mathrm{Sm}-\mathrm{O}-\mathrm{Sm}-\mathrm{O}$ rings formed by the bridging structure. The distance between two Sm atoms is $4.379(2) \AA$. Each samarium atom is coordinated by six carboxylate and three water molecules. The water molecules are involved in an extensive network of hydrogen bonds amongst themselves and with the non-bridging atoms of the ligands (O5 and O11). It appears that, in addition to the oxygen bridge bonds involving the malonate ligand, the crystal structure is stabilized through extensive hydrogen bonding involving the carboxylate groups and water molecules to form a three-dimensional network (Fig. 6). In all the hydrogen bonds, the water oxygens (O2, $\mathrm{O} 3, \mathrm{O} 4)$ act as donor atoms and the carboxylate or other water oxygens act as acceptor atoms. Furthermore, additional hydrogen bonds occur between a carboxyl group and a water molecule. The structure has both intra- and intermolecular hydrogen bonds of the type $\mathrm{O}-\mathrm{H} \cdots \mathrm{O}$. The lengths and angles along with the symmetry codes are given in Table 4.

For the malonate ligand, the dihedral angle between the planes O9-C10-O11-C12 and C12-O13-C14-O15 is $36.1(4)^{\circ}$. Two malonate units are crystallographically independent and with different arrangements; e.g., S2 and S3 (Fig. 1). The S2 mode is characterized by the malonate ligand bridging two samarium atoms, acting as both a bidentate chelate $\left({ }^{-} \mathrm{O}_{2} \mathrm{CCH}_{2} \mathrm{CO}_{2}{ }^{-}\right)$and monodentate $\left({ }^{-} \mathrm{O}_{2} \mathrm{C}-\right.$ ) ligand to samarium. The chelate ring has a boat conformation while the monodentate function adopts an anti-syn conformation. In the S3 arrangement, the malonate ligand bridges four Sm atoms through two bidentate four-membered chelate-rings as well as two monodentate interactions of anti-anti conformation. The $\mathrm{C}-\mathrm{O}$ bond distances and $\mathrm{O}-\mathrm{C}-\mathrm{O}$ bond angles in both malonate ligands are 1.253(5)-1.270(7) $\AA$ and $120.8(5)-123.6(6)^{\circ}$, respectively. These values are in agreement with previously reported malonate-lanthanide complexes [15, 42-44].

The structure of $\mathbf{1}$ shows a three-dimensional arrangement of samarium units bridged by malonate groups (Figs. 5, 6), which result from the cross-linking of the single chains that run parallel to $a c$ plane (Fig. 7) and the double twisted zig-zag chains that extend in the $a b$ plane (Fig. 8).

The samarium-to-water oxygen bond lengths are 2.487(5)-2.528(4) $\AA$, which are slightly longer than the samarium-to-carboxylate oxygen lengths (2.370(4)$2.445(3) \AA)$. This is consistent with the coordination ability of water being weaker than that of the carboxylates. 


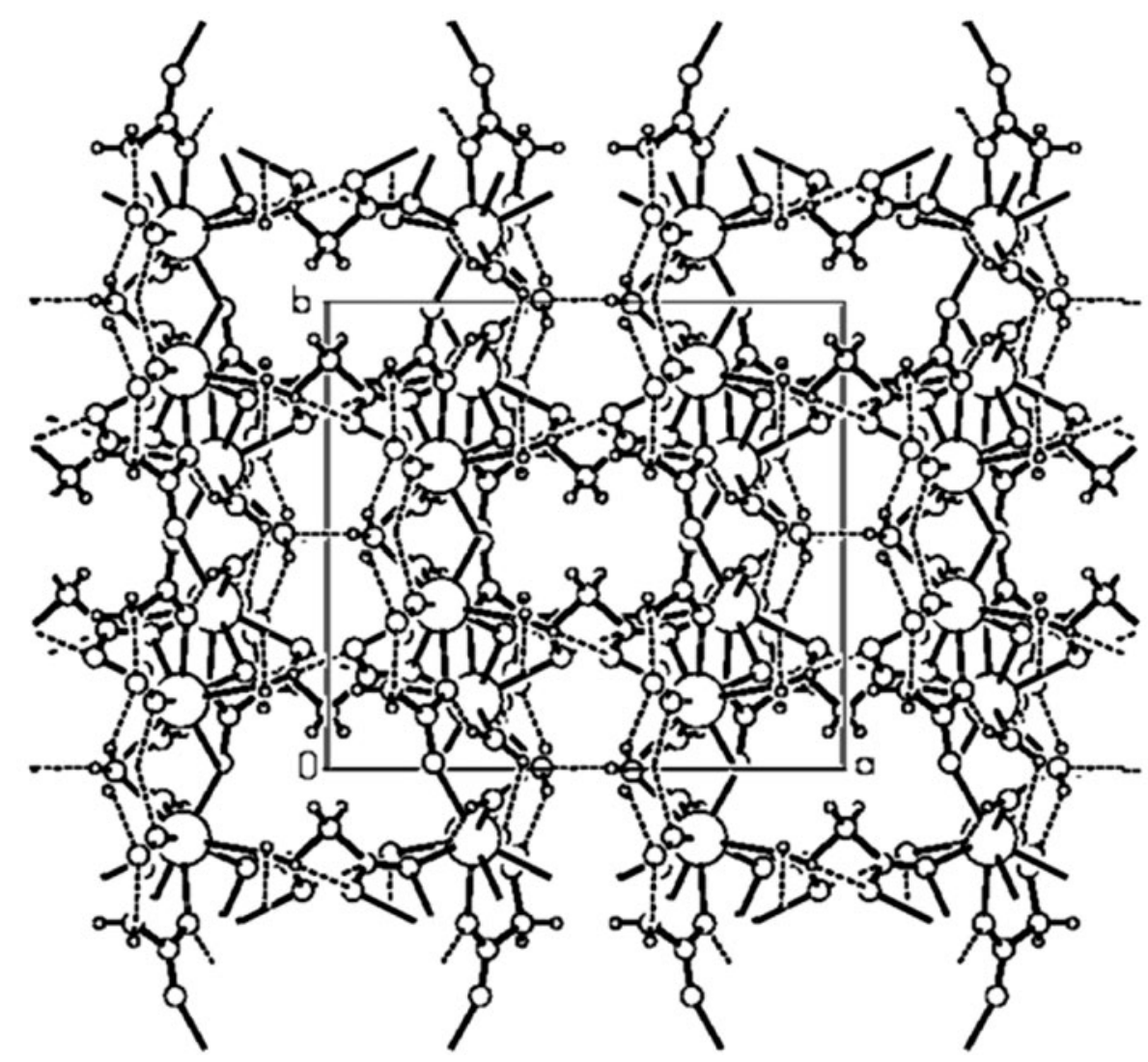

Fig. 6 Projection of the structure down $c$ axis. Dashed lines correspond to hydrogen bridging

Table 4 Intra- and intermolecular hydrogen bonds of $\mathbf{1}$; lengths, angles and symmetry codes

\begin{tabular}{llll}
\hline $\mathrm{D}-\mathrm{H} \cdots \mathrm{A}$ & $\mathrm{D}-\mathrm{A}(\mathrm{A})$ & $\mathrm{D}-\mathrm{H} \cdots \mathrm{A}\left(^{\circ}\right)$ & Symmetry codes \\
\hline $\mathrm{O} 2-\mathrm{H} 2 \mathrm{~A} \cdots \mathrm{O} 11$ & 2.7158 & 114 & $1 / 2-\mathrm{x}, 1 / 2-\mathrm{y}, 1-\mathrm{z}$ \\
$\mathrm{O} 2-\mathrm{H} 2 \mathrm{~B} \cdots \mathrm{O} 5$ & 2.8472 & 174 & $1 / 2+\mathrm{x}, 1 / 2-\mathrm{y}, 1 / 2+\mathrm{z}$ \\
$\mathrm{O} 4-\mathrm{H} 15 \mathrm{~B} \cdots \mathrm{O} 13$ & 2.7288 & 153 & $1 / 2-\mathrm{x}, 1 / 2-\mathrm{y},-\mathrm{z}$ \\
$\mathrm{O} 3-\mathrm{H} 18 \mathrm{~A} \cdots \mathrm{O} 3$ & 2.8474 & 148 & $-\mathrm{x}, 1-\mathrm{y},-\mathrm{z}$ \\
$\mathrm{O} 4-\mathrm{H} 15 \mathrm{~A} \cdots \mathrm{O} 9$ & 2.8117 & 113 & $\mathrm{x}, 1-\mathrm{y},-1 / 2+\mathrm{z}$ \\
$\mathrm{O} 3-\mathrm{H} 18 \mathrm{~B} \cdots \mathrm{O} 11$ & 2.7327 & 137 & $\mathrm{x}, 1-\mathrm{y},-1 / 2+\mathrm{z}$ \\
\hline
\end{tabular}

\section{Conclusion}

A good quality single crystal of samarium malonate hydrate suitable for structural studies was produced by the gel technique. Single crystal studies revealed that the compound is $\left[\mathrm{Sm}_{2}\left(\mathrm{C}_{3} \mathrm{H}_{2} \mathrm{O}_{4}\right)_{3}\left(\mathrm{H}_{2} \mathrm{O}\right)_{6}\right]_{\mathrm{n}}$. All the characteristic bands expected for the compound are observed in the FT-IR spectrum. Thermogravimetric study showed that the compound is thermally stable up to $133{ }^{\circ} \mathrm{C}$. Above $133{ }^{\circ} \mathrm{C}$, 1 undergoes three-stages of thermal decomposition and ultimately gets reduced to samarium oxide at $810^{\circ} \mathrm{C}$.

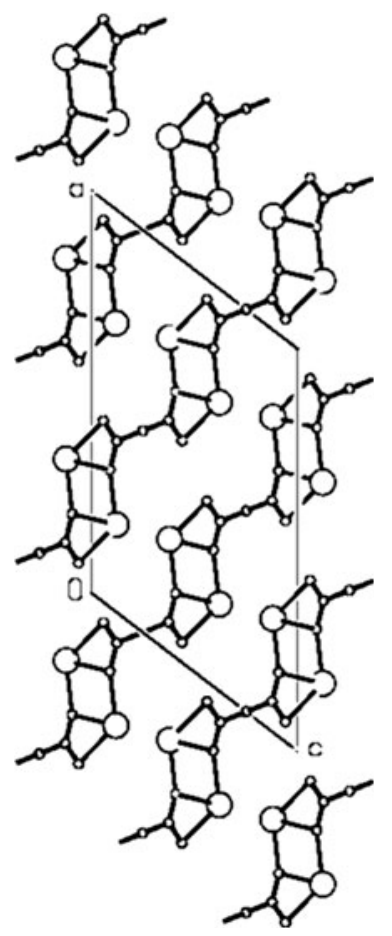

Fig. 7 Projection of the single chain down $b$ axis. Malonate ligand $\mathrm{S} 2$, water molecules and $\mathrm{H}$ atoms have been omitted for clarity 


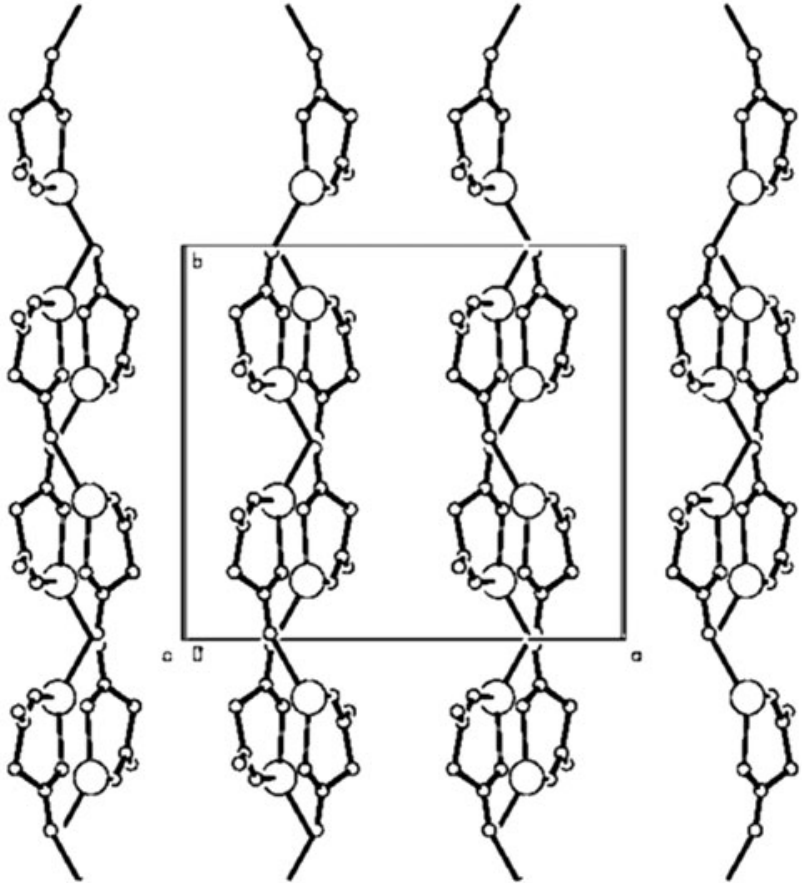

Fig. 8 Projection of the independent single chain down $c$ axis. Malonate ligand S3, water molecules and $\mathrm{H}$ atoms have been omitted for clarity

\section{Supplementary Material}

CCDC no. 215588 contains the supplementary crystallographic data for this paper. These data can be obtained free of charge at www.ccdc.cam.ac.uk/conts/retrieving.html [or from the Cambridge Crystallographic Data Centre (CCDC), 12 Union Road, Cambridge CB2 1EZ, UK; fax: +44(0)1223-336033; email: deposit@ccdc.cam.ac.uk].

Acknowledgments The authors would like to express their thanks to DST, Government of India, for financial assistance under project SP/I2/FOO/93. Also, BHD and MM would like to thank the SJB Institute of Technology and the University of Mysore for their kind support and encouragement.

\section{References}

1. J.R. Barkley, L.H. Brixner, E.M. Hogan, R.K. Waring, J. Ferroelectr. 3, 191 (1972)

2. J. Sapriel, R. Vacher, J. Appl. Phys. 48, 1191 (1977)

3. R.P. Rao, in Second International School on Excited States of Transition Elements, Karpacz, Poland, 2-6 Sept 1991. (World Scientific, Singapore, 1992), p. 231

4. Raj Kamal, K.P. Maheswari, R.L. Sawhney, Laser opticsReviews in contemporary physics, (Wiley Eastern Limited, India, 1992), p. 70

5. J. Mares, Second International School of Excited States of Transition Elements, Karpacz, Poland, 2-6 Sept 1991. (World Scientific, Singapore, 1992) p. 192

6. J. Sun, C. Chen, Z. Quin, J. Lumin. 40, 246 (1988)
7. H. Shing-Hua, T.C.W. Mak, Z. Kristallogr. 190, 305 (1990)

8. S.M. Dharmaprakash, P. Mohanrao, Cryst. Res. Technol. 23(3), k143 (1988)

9. H. Shing-Hua, G.D. Zhon, T.C.W. Mak, J. Cryst. Spect. Res. 21, 127 (1991)

10. B.H. Doreswamy, M. Mahendra, M.A. Sridhar, J. Sasidharaprasad, P.A. Varughese, K.V. Saban, G. Varghese, J. Mol. Struct. 659, 81 (2003)

11. P.A. Varughese, K.V. Saban, J. George, I. Paul, G. Varghese, J. Mater. Sci. 39, 6325 (2004)

12. C. Bromant, M.S. Wickeleder, G. Meyer, Z. Anorg. Allg. Chem. 627, 768 (2001)

13. M.P. Gupta, K. Banerjee, Z. Kristallogr. 162, 277 (1983)

14. P.N. Kotru, K.K. Raina, M.L. Koul, J. Mater. Sci. 21, 3933 (1986)

15. A. Karipides, J. Ault, A.T. Reed, Inorg. Chem. 16, 3299 (1997)

16. E. Hansson, Acta Chem. Scand. 27, 2827 (1973)

17. E. Hansson, Acta Chem. Scand. 27, 2813 (1973)

18. E. Hansson, Acta Chem. Scand. 27, 2841 (1973)

19. R. Hamalainen, A. Pajumen, Suom. Kemistil. B 46, 285 (1973)

20. N.J. Ray, B.J. Hathaway, Acta. Crystallogr. Sect. B 38, 770 (1982)

21. D. Chattopadhyay, S.K. Chattopadhyay, P.R. Lowe, C.H. Schawalbe, S.K. Mazumber, A. Rana, S. Ghosh, J. Chem. Soc. Dalton Trans. 913 (1993)

22. K.R. Butler, M.R. Snow, J. Chem. Soc. Dalton. Trans. 251 (1976)

23. I. Gil de Muro, F.A. Mautner, M. Insausti, L. Lezama, J.L. Pizarro, M.L. Arriortua, T. Rojo, Eur. J. Inorg. Chem. 935 (1999)

24. K. Matsumoto, H. Kuroya, Bull. Chem. Soc. Jpn. 45, 1755 (1972)

25. K.R. Butler, M.R. Snow, J. Chem. Soc. Dalton. Trans. 259 (1976)

26. H.K. Henisch, Crystal growth in gels (Pennsylvania University Press, London, 1970)

27. Z. Otwinowski, W. Minor, in Methods in Enzymology, vol 276, ed. by C.W. Jr Carter, R.M. Sweet (Academic Press, New York, 1997), pp 307-326

28. S. Mackay, C.J. Gilmore, C. Edwards, N. Stewart, K. Shankland, maXus: Computer Program for the Solution and Refinement of Crystal Structures, (MacScience, Tokyo and The University of Glasgow, Glasgow, 1999)

29. G.M. Sheldrick, SHELXS-97: Program for Crystal Structure Solution (University of Gottingen, Gottingen, 1997)

30. G.M. Sheldrick, SHELXL-97: Program for the Refinement of Crystal Structures (University of Gottingen, Gottingen, 1997)

31. J.T. Edsall, J. Chem. Phys. 5, 508 (1937)

32. L.J. Bellamy, The IR Spectra of Complex Molecule, vol. 1 (Chapman and Hall, London, 1975)

33. K. Nakamoto, IR and Raman Spectra of Organic and Coordination Compounds, 5th edn. (Wiley, New York, 1977)

34. B. Benmerad, A. Guehria-Laidoudi, G. Bernardinelli, F. Balegroune, Acta Cryst. C 56, 321 (2000)

35. C. Ruiz-Perez, J. Sanchiz, M. Hernandez-Molina, F. Lloret, M. Julve, Inorg. Chim. Acta 298, 202 (2000)

36. C. Ruiz-Perez, M. Hernandez-Molina, J. Sanchiz, T. Lopez, F. Lloret, M. Julve, Inorg. Chim. Acta 298, 245 (2000)

37. I. Gil de Muro, F.A. Mautner, M. Insausti, L. Lezama, M.I. Arriortua, T. Rojo, Inorg. Chem. 37, 3243 (1998)

38. J.G. Kang, S.K. Yoon, Y. Sohn, Y.S. J.G. Kim, Y.D. Kim, I.H. Suh., J. Chem. Soc, Dalton Trans. 1467 (1999)

39. U. Casellato, R. Graziani, R. P. Bonomo, A.J.D. Bilio, J. Chem. Soc. Dalton Trans. 23 (1991)

40. C. Bellito, F. Federichi, S.A. Ibrahim, Chem. Mater. 10, 1076 (1998)

41. A. Cabeza, M.A.G. Aranda, S. Bruque, J. Mater. Chem. 9, 571 (1999)

42. E.V. Brusau, G.E. Narda, J.C. Pedregosa, G. Echeverrria, G.M. Punte, J. Solid. State Chem. 143, 174 (1999) 
43. T. Lis, J. Matuszewski, J. Chem. Soc. Dalton Trans. 996 (1980)

44. Z.M. Wang, L.J. van de Burgt, G.R. Choppin, Inorg. Chim. Acta 310, 248 (2000)
45. C.K. Johnson, ORTEP-II A: Fortran Thermal-Ellipsoid Plot Program, Report ORNL-5138 (Oak Ridge National Laboratory, Oak Ridge, 1976) 